\title{
Study on Internal Control Construction of Enterprise Accounting
}

\author{
Qian Liu \\ Chongqing Vocational Institute of Engineering, Chongqing, 402260, China
}

\begin{abstract}
Keywords: Enterprise, Accounting, Internal control, Construction
\end{abstract}
\begin{abstract}
Internal accounting control level has become a key factor of enterprise development. To enhance decision-making ability, effectively eliminate fund obstacle and make sure financial conditions comply with standards, enterprises must enhance internal accounting control construction force and then accelerate enterprise development. However, many defects exist when enterprises construct internal accounting control, so internal accounting control still needs perfecting. Therefore, this paper studies internal control construction of enterprise accounting, and proposes the measures to accelerate internal control to boost internal control and management ability of enterprise accounting and achieve significant economic growth.
\end{abstract}

\section{Introduction}

As China's economic system keeps on reforming and deepening, enterprise development is confronted with new challenges. To gain favorable development, enterprises must enhance internal accounting control construction and effectively manage enterprise finance. Enterprise should regard internal accounting control as an important part in management work, improve accounting quality through resource optimization and then guarantee improvement of management ability under internal accounting control. However, some enterprises have weak internal accounting control construction awareness and imperfect internal control system, so enterprises are faced with numerous challenges during constructing internal accounting control. Some enterprises suffer many problems in internal control construction due to weak internal control awareness and imperfect internal control system. Thus, enterprises must attach importance to internal control and adopt corresponding measures to improve internal control construction.

\section{Overview about internal accounting control}

Since the reform and opening-up policy was implemented, development and innovation in China have achieved great results, but meanwhile economic prosperity causes internal control construction of enterprise accounting is inconsistent with realistic economic environment. To effectively improve this, enterprises must reinforce internal accounting control.

China has enacted corresponding provisions on the concept of internal accounting control. Fundamental Norms stipulate that, "internal accounting control refers to a series of control measures, methods and procedures which aim to improve accounting information quality, guarantee asset safety and completeness and make sure relevant laws and systems are implemented.” Internal accounting control actually directly utilizes capital operation as the object and offers guarantee for effective capital flow. Of course, capital flow runs through the whole process of economic activities of enterprise. In this way, internal accounting control can turn into the core and foundation of internal control. Managers regulate enterprise business activities through rational application of accounting information and internal accounting control so as to reach the purpose of benefit maximization.

Besides, the design of internal accounting control also should follow certain principles. Firstly, enterprises should formulate internal accounting control system in accordance with relevant national laws ad regulations. Secondly, internal accounting control must cover each link of enterprise business activities and management. Thirdly, to effectively defend various risks, enterprises should be prudent to head off dangers. Finally, enterprises should follow cost-benefit principle and reach the best effect through rational control. 


\section{Importance of internal accounting control}

Internal accounting control is the core of corporate internal control. Modern enterprise management lays stress on enhancing internal accounting control and optimizing internal structure. Under the guidance of systems, doing well internal and financial auditing work, strengthening financial management level and improving economic income have become the mainstream.

In current society, internal accounting control system is not very sound. At present, the number of new enterprises is on the rise year by year. However, many enterprises cannot do internal control well. In particular, some medium and small enterprises are not very familiar with internal control and lack sound internal control system, so enterprise accounting information quality is lack of recognition. Nonstandard internal accounting control will trigger a series of problems. For instance, weak quality of accounting personnel will result in low accounting management level. Accounting control of small and medium enterprises also involves cost accounting. Due to the limits of cost and personnel, management is not standard. Thus, financial and accounting personnel should own professional skills and information technology in order to manage small and medium enterprises in an all-round way. Therefore, enhancement of internal accounting control construction can not just improve enterprises' ability to resist all kinds of risks, but also perfect internal management. In one word, internal accounting control quality plays a significant role for enterprise development.

\section{Problems existing in internal accounting control}

Insufficient informatization and supervision strength. The emphasis of internal accounting control lies in internal audit. Most enterprises pay insufficient attention to audit, so internal control of enterprises fails to reach an ideal effect. Some enterprises fail to fully equip internal audit department and personnel, and even some enterprises let accounting director or other personnel to manage the audit department. Thus, self-supervision exists, and the important function of internal audit cannot be reached $^{[1]}$. Enterprises should supervise production and management and discover problems in time. Enterprises should set up internal audit department, ensure validity, authenticity and rationality of financial work, perfect auditing system and really reveal authority of audit. In addition, enterprises should supervise other departments, discover problems of each post and business in time and rationally adjust each post and business.

Comprehensive quality of accounting personnel needs improving. Since enterprises have developed prosperously in recent years, the accounting team also grows and expands. However, the training and ideological education of accounting personnel fall behind, so the quality of accounting personnel is uneven. Because accounting personnel are not serious and lack initiative in work and there is the lack of initiative talents, they cannot adapt accounting control and business development, which results in economic loss. Although many enterprises train accounting personnel, the training lacks pertinence and tends to formalization. Therefore, enterprises should overall cognize the importance of internal accounting control from different perspectives and the quality of relevant personnel should improve.

Imperfect internal accounting control system. According to the survey of related departments, more than $20 \%$ enterprises nationwide lack the ability to overall plan internal control, fail to well supervise business contents and fail to properly handle beforehand, in-process and post-event control of enterprise finance. All these influence overall effect of internal control. At present, Chinese enterprises have some wrong ideas about internal accounting control. Typically, they consider the establishment of internal accounting control system will affect diversity and flexibility of enterprise decision-making. Some enterprises have no sound internal system in internal control construction process, so internal management is chaotic and their ability to resist risks insufficient. Meanwhile, enterprise cost cannot be reflected truly and effectively, and resource waste will appear ${ }^{[2]}$. In order to perfect internal control, financial department shoulders important functions and concerns the development of future of an enterprise.

Weak internal accounting control awareness. Although enterprises have enhanced management of financial department in recent years, some enterprises consider internal accounting 
control aims to basically supervise financial work due to their weak internal control awareness, so their financial audit is weak. Some leaders believe that internal accounting control is not essential; it is unnecessary to record income and expenses of project funds, as long as the results are correct. Besides, they think budget department can well manage financial work, so the audit development is not so important; internal control can be managed and supervised by budget and finance departments.

If internal control awareness of an enterprise is weak, it is hard to ensure internal control effect and seriousness in enterprise development process. All-round internal accounting system will not restrict enterprise development; on the contrary, it will facilitate long-term benign development. Thus, it is urgent to actively implement internal accounting system.

\section{Measures to enhance internal accounting control construction}

To perfect internal accounting control system. To obtain favorable performance of internal control, enterprises must establish perfect internal control system and implement internal control under the guidance of system. Perfection of internal control system plays an important role in improving accounting information quality. Sound internal control system must include supervision system and sound information disclosure. Enterprise risks can be reduced only when enterprises supervise enterprise operation and management and disclose the problems. For internal control system, scientific financing mode must be adopted to rationally invest and manage funds effectively and safely. Enterprises may reach the effect of internal control through optimizing funds and expenditures and provide beneficial basis for enterprise development. Financial personnel should prepare budget according to actual conditions in budgeting process and make adjustments in accordance with relevant changes. Thus, sound budget system should cover assessment of budget in each stage and standardization of budget behaviors in order make sure actual operation situations comply with each budge index and reach reliable budget result. In management process, enterprises should be based on scientific theoretical foundation. Coherent and complete inner control system will offer beneficial guarantee for enterprises.

To enhance internal accounting control awareness. Although management level of some enterprises has internal control awareness, the management level fails to regard it as a strategic means of enterprise operation and only considers it is the mater of a department, without the need of joint efforts of all employees. If managers lack internal control awareness, the employees will be affected. If an enterprise fails to own favorable internal control system on the whole, the enterprise will circulate the inherent business mode and have no any breakthrough. Only when enterprises enhance internal control awareness can they drive internal control construction. An enterprise in Jiangsu Province realized the importance of internal control. To improve internal control awareness of all employees, the management level took the lead in learning knowledge theory of internal control ${ }^{[3]}$. The thought of enterprise leaders change positively, and the leaders lead the employees to learn together. The enterprise also carries out internal control training for accounting at regular intervals to learn modern enterprise operation and management philosophy and know the knowledge of internal control construction. Thus, internal control awareness of all employees improves and a favorable internal control environment is created. Thus, the enterprise develops under dual functions of thorough production and internal management.

To strengthen information construction force. With rapid economic development, computer informatization is extensively applied. The fusion of information technology and enterprise finance has not been a new challenge. Nevertheless, internal accounting control means still fall behind and fail to keep up with the era. Many enterprises still adopt manual internal accounting control method. Thus, information errors appear continuously, so the control effect is affected and events cannot be controlled and accounted fast. In a bid to boost accounting information quality and do internal control we, information construction strength must be enhanced. State-owned enterprises should continuously accelerate audit information construction, achieve digital audit and create auditing modes. Internal audit department should regard financial accounting software database as the beginning, take audit information system as the platform and deem accuracy, norm and effectiveness as the objective to grasp the main processes and further perfect audit information system 
construction $^{[4]}$. Enterprises should take software application as the audit information construction bridge and extend audit information to each link of enterprise management.

To boost comprehensive quality of accounting personnel. The implementation effect of internal accounting control system depends on comprehensive quality of enterprise employees. The survey results show comprehensive quality of enterprise employees exerts a direct influence on the effect of internal accounting control, and that higher quality of employees will bring better implementation results. Improvement of employee quality may start from the following aspects. Firstly, establish training mechanism; secondly, introduce competition mechanism; finally, enhance enterprise culture construction and combine internal accounting control system and enterprise culture to boost comprehensive quality of accounting personnel. Enterprise development has far-reaching influence on whole economic construction and itself. Improvement of comprehensive quality of accounting personnel is an inevitable choice for enterprises to achieve future long-term development. To realize internal accounting control objective, a major approach is to optimize comprehensive quality of accounting personnel so that enterprises can do internal accounting control well and achieve better development ${ }^{[5]}$.

\section{Conclusions}

To adapt market embroilment and obtain higher profits, enterprises must alter management idea and regard internal control as the core content of enterprise management and operation. Financial work is closely related to enterprise development, so accounting information quality must be guaranteed. Since internal control has great influence on accounting information quality, enterprises should start from the global situation, do internal control well, formulate strategies for accounting information quality and guarantee authenticity and reliability of accounting information so as to improve core competitiveness of enterprises. Internal accounting control construction also needs to specify duties of each post and overall control enterprise cost, audit, risk, budget and planning through cooperation of different departments. In this way, enterprises can stick to people first and take the way of sustainable development under legal conditions.

\section{References}

[1] Wu Xingfeng, Study on Internal Business Accounting Control Construction. Modern Economic Information, 2011(19):176.

[2] Deng Huiling, Thought on Internal Business Accounting Control Construction. Money China, 2012(4):106-106.

[3] Duan Weiyan, Analysis of Problems of Internal Business Accounting Control and Perfection Measures. Foreign Investment in China (Second Half Month), 2013(10):108-109.

[4] Song Changying, Analysis of How to Enhance Internal Business Accounting Control System Construction. Money China (Academic), 2010(23):340-341.

[5] Hong Zhangyi, On Effective Perfection of Internal Business Accounting Control System. Modern Economic Information, 2011(14):157. 